\title{
EVALUACIÓN HIGIÉNICA PREVIA DE ACRILAMIDA EN AIRE DURANTE LA PREPARACIÓN DE GEL DE POLIACRILAMIDA (PAA) EN UN LABORATORIO DE GENÉTICA
}

\author{
ANTONIO BLEIN SÁNCHEZ DE LEÓN *, \\ MARÍA VICTORIA ARRUGA LAVIÑA ** \\ (*) GPR Ingeniería Integral de Prevención, S. L. \\ (**) Laboratorio de Citogenética y Genética Molecular \\ Facultad de Veterinaria. Zaragoza
}

\begin{abstract}
RESUMEN
Objetivos: Conocer el nivel aproximado de concentración en aire de Acrilamida, cancerígeno y mutagénico tipo 2, durante la preparación del gel de Poliacrilamida en el Laboratorio, para verificar si la situación higiénica es tolerable, o si no lo es, para tomar medidas preventivas inmediatamente, antes de llevar a cabo una evaluación detallada con arreglo a UNE-EN 689, con un coste notablemente mayor.
\end{abstract}

Metodología: Una vez seleccionadas las etapas de preparación del gel donde hay emisión de Acrilamida, el método higiénico seguido ha sido el PV2004, de NIOSH, para la toma de muestra y el análisis.

Resultados: La concentración de Acrilamida detectada en la fase de pesada es de $723 \%$ del Valor Límite de Exposición Profesional para exposición diaria y del 145\% del Valor Límite de Exposición Profesional para Corta Exposición. En la fase de agitación no se detectó Acrilamida en la muestra.

Conclusiones: Es necesario tomar medidas preventivas inmediatamente. Se proponen varias medidas. Una vez aplicadas, se recomienda realizar la evaluación higiénica según UNE-EN 689.

\section{PALABRAS CLAVES}

Laboratorios, higiene industrial, cancerígenos, acrilamida..

\section{ABSTRACT}

Aims: To know the approximate level of Acrylamide, carcinogenic type 2, in air, during the preparation of Polyacrylamide-Gel in the laboratory, in order to determine if the occupational hygiene situation is acceptable or not, in order to, if not, to implement immediately preventive measurements, before carring out an hygienical assessment following the UNE-EN 689 standard, with much higher costs.

Methods: After the selection of the gel-preparation stages, where evaporation of Acrylamide takes place, the followed method was PV2004, from $\mathrm{NIOSH}$, for the sample collection and for the analyse.

Results: The detected level of Acrylamide in the weighting stage is $723 \%$ of the TLV-TWA and $145 \%$ of the TLV-C. In the stirring stage there was found no Acrylamide .

Conclusions: It is necessary to implement immediately preventive measurements. Some of them are proposed. Once implemented it is recommended to carry out an hygienical assessment according to UNE-EN 689.

\section{KEY WORDS}

Laboratory, occupational hygiene, carcinogenics, acrylamide. 


\section{INTRODUCCIÓN}

En los Laboratorios de Genética se manipulan sustancias químicas peligrosas. La Acrilamida se ha revelado como una de las sustancias más peligrosas utilizadas en estos laboratorios.

La Acrilamida, 2-propenamida, es un sólido cristalino blanco, fácilmente soluble en agua, metanol, etanol y acetona. Su fórmula química es $\mathrm{CH}_{2} \mathrm{CHCONH}_{2}$. Es insoluble en heptano y benceno. Funde a $84,5{ }^{\circ} \mathrm{C}$ y tiene una presión de vapor de $0,9331 \mathrm{~Pa}$ a $25^{\circ} \mathrm{C}^{1,2}$.

La Acrilamida se usa con frecuencia en los dichos laboratorios de Genética y en otros Biolaboratorios para la preparación de geles de Poliacrilamida, que se utilizan como soporte en Electroforesis para separar ácidos nucleicos y proteinas ${ }^{3,4,5}$. Frente al gel de Agarosa, que se utiliza para el mismo fin, presenta la ventaja de tener un mayor poder de resolución, siendo capaz de diferenciar bandas de DNA que difieran únicamente en dos pares de bases.

Sin embargo, la manipulación de Acrilamida presenta varios peligros para la salud de los trabajadores del laboratorio. Es nocivo por inhalación y en contacto con la piel. También es tóxico por ingestión. Puede producir sensibilización en contacto con la piel ${ }^{6,7,8}$. Además, puede causar cáncer ${ }^{9}$ (cancerígeno 2A) y alteraciones genéticas hereditarias ${ }^{10}$ (mutagénico 2A, según IARC).

Este artículo pretende contribuir al mejor conocimiento del riesgo higiénico al que están sometidos las personas que realizan la preparación del mencionado gel, mediante la evaluación aproximada de la exposición por inhalación a Acrilamida en un Laboratorio de Genética.

Si bien actualmente se dispone de tecnologías alternativas que permiten la perfecta diferenciación de ácidos nucleicos mediante secuenciación, estas requieren instrumentación de alto coste. Por ello es previsible que esta técnica de Electroforesis en gel de Poliacrilamida se siga utilizando durante bastante tiempo en un amplio número de laboratorios.

Este trabajo se enmarca en la colaboración de GPR Ingeniería Integral de Prevención, S. L. con la Universidad de Zaragoza.

\section{MATERIALES Y MÉTODOS}

La finalidad de la electroforesis en gel de Poliacrilamida que se realiza en este laboratorio es la separación y visualización de ADN obtenido de ejemplares de Perdiz roja española (Alectoris rufa), amplificado mediante PCR (Polymerase Chain Reaction).

\subsection{Proceso de preparación del gel de Poliacrila- mida}

La preparación del gel de Poliacrilamida consiste fundamentalmente en disolver en agua una mezcla de Acrilamida y Bis-Acrilamida en una determinada proporción, que es función del grado de reticulación deseado en el polímero, y añadir Urea, Amonioper-

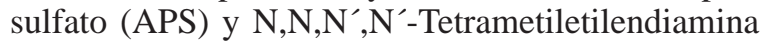
(TEMED). La función de la Urea es servir de desnaturalizante, mientras que el APS y el TEMED actúan como catalizadores y la Bis-Acrilamida como co-monómero. Un ligero calentamiento hasta unos $45{ }^{\circ} \mathrm{C}$ favorece la disolución y acelera el comienzo de la reacción de polimerización. A continuación se vierte mediante la jeringuilla la mezcla así preparada entre placas de vidrio con una separación prefijada y se deja polimerizar, obteniéndose un gel del espesor deseado. El TBE es un tampón habitual compuesto de TRIS, Ácido Bórico y EDTA.

\section{Materiales y aparatos}
A. Agua miliQ
B. TBE $\times 5$
C. APS
D. Acrilamida
E. Bis-Acrilamida
F. Urea
G. TEMED
H. Placas de vidrio
I. Papel Celofán
J. Separadores (plancha calibrada de PVC)
K. Jeringuilla (sin aguja)
L. Vitrina de gases
M. Horno Microondas
N. Espátula vibradora
O. Vaso de precipitados

\section{Metodología (etapas)}
a) Preparar disolución de Urea: Pesar y disolver urea APS

b) Preparar disolución de APS: Pesar y disolver

c) Pesar Acrilamida y Bis-Acrilamida

d) Disolver ambas en agua con TEMED y agitar durante 2 horas hasta disolución completa (vaso tapado) 

$45^{\circ} \mathrm{C}$

e) Calentar d) en horno Microondas hasta unos

f) Preparar las placas de vidrio (rectangulares) con los separadores, cerrándolas con papel celofán por tres lados

g) Verter e) con la jeringuilla entre las placas en caliente, en vitrina de gases

h) Dejar enfriar y polimerizar en la vitrina de gases durante dos horas

i) El exceso de e) se deja enfriar y polimerizar también en la vitrina durante dos horas

Una vez polimerizada, la Acrilamida ha pasado a formar parte del polímero, que no presenta los riesgos del monómero. Por esto el riesgo se centra en la manipulación de la Acrilamida en el proceso de preparación del gel de Poliacrilamida, previo a la electroforesis.

\subsection{Determinación de la exposición a Acrilamida} aire

a) Método de determinación de Acrilamida en

Para realizar esta determinación se ha seguido el método OSHA PV2004 ${ }^{11}$, por ser respecto a otros métodos ${ }^{12,13}$ el más reciente y el de menor límite de detección.

Las muestras se obtienen haciendo pasar durante un tiempo determinado un caudal de aire conocido por medio de una bomba, a través de un tubo que contiene un filtro de fibra de vidrio y dos secciones del absorbente XAD-7. La bomba se calibra antes y después de la toma de muestra, debiendo dar una diferencia entre ambas inferior al 5\% para que la medición se considere válida. El tubo se conserva a $4{ }^{\circ} \mathrm{C}$ hasta su análisis. Para proceder al mismo, las muestras son desorbidas con una solución que contiene $5 \%$ de metanol y $95 \%$ de agua y se analizan mediante Cromatografía Líquida de Alta Resolución (HPLC), usando un detector UV.

\section{b) Estrategia de muestreo}

Las etapas del proceso de preparación de gel de Poliacrilamida que presentan riesgo de inhalación de Acrilamida son la c y d, esto es, la pesada del producto, y la disolución y agitación durante dos horas, que se realizan actualmente ambas fuera de vitrina de gases.

Por ello la toma de muestra se centra en dichas dos etapas. Al no disponer de datos previos, se ha decidido llevar a cabo inicialmente una medición para la evaluación aproximada siguiendo lo indicado en la Norma UNE-EN $482^{14}$.

En el caso de la etapa d), disolución y agitación durante 2 horas, se ha realizado un muestreo ambiental, puesto que la operación es estática y sin presencia permanente de la persona. Mientras que para la etapa c) se ha optado por un muestreo personal. Al ser la duración de dicha etapa, pesada de Acrilamida y Bis-Acrilamida, de alrededor de 5 minutos y prescribir el método PV2004 un tiempo

Tabla 1. Parámetros de la toma de muestra

\begin{tabular}{|c|c|c|}
\hline Concepto & Etapa c) Pesada & Etapa d) Agitación \\
\hline Tipo de muestreo & Personal & Ambiental \\
\hline Bomba: Tipo / N ${ }^{\circ}$ de serie & Apex / 0531477 & Vortex / 041286 \\
\hline Calibrador: Tipo / N ${ }^{\circ}$ Serie & Gilian / 004598 & Gilian / 004598 \\
\hline Caudal inicial (L/min) & 1,005 & 0,014 \\
\hline Caudal final (L/m in) & 0,990 & 0,993 \\
\hline Caudal medio (L/min) & 0,997 & 120 \\
\hline Tiempo de muestreo (min) & 120 & 119,2 \\
\hline Volumen (L) $^{\text {Temperatura }{ }^{\circ} \mathrm{C}}$ & 119,7 & 23 \\
\hline Humedad relativa (\%) & 21 & 55 \\
\hline
\end{tabular}


de toma de muestra de 120 minutos, se ha optado por repetir la etapa c) sucesivas veces hasta alcanzar dicho tiempo.

Los parámetros de la toma de muestras se reflejan en la tabla 1.

Las muestras de las dos etapas han sido tomadas en días distintos, separados por una semana, con el objeto de evitar posibles interferencias.

\section{c) Determinación analítica}

La determinación analítica ha sido realizada por el laboratorio Grupo Interlab, S. A., acreditado por ENAC con arreglo a la Norma UNE-EN-ISO/IEC 17025, siguiendo el método indicado.

\section{RESULTADOS}

Una vez realizada la determinación analítica, para el cálculo de la concentración se utiliza la expresión:

$$
C=\frac{M}{V}
$$

Siendo: C: Concentración media de Acrilamida en aire durante el periodo considerado

M: Masa de Acrilamida detectada en el análisis y V: Volumen aspirado por la bomba

En la Tabla 2 se recogen los resultados analíticos de la medición15.

A fin de conocer si existe riesgo higiénico se recurre a la comparación con valores de referencia: los valores límite de exposición profesional (valores límite ambientales). Para la acrilamida estos están establecidos por diferentes organizaciones de varios países. En España tienen valor legal los publicados por el Instituto Nacional de Seguridad e Higiene en el Trabajo (INSHT).

En la tabla 3 se muestran los valores límite para la Acrilamida propuestos por diversas organizaciones.

Tabla 2. Resultados analíticos de la medición

\begin{tabular}{|c|c|c|}
\hline Concepto & Etapa c) Pesada & Etapa d) Agitación \\
\hline Cantidad analizada ( $\mu \mathrm{g})$ & 26 & N.D. $*$ \\
\hline Volumen $\left(\mathrm{m}^{3}\right)$ & 0,1197 & 0,1192 \\
\hline Concentración (mg/m³ $\left.{ }^{3}\right)$ & 0,217 & --- \\
\hline
\end{tabular}

*N.D. : No Detectado (por debajo del límite de detección del método)

Tabla 3. Límites ambientales según distintas organizaciones

\begin{tabular}{|c|c|c|}
\hline Organización/País & Tipo & Valor Límite \\
\hline ACGIH / EEUU & TWA & $0,03 \mathrm{mg} / \mathrm{m}^{3}$ \\
\hline NIOSH / EEUU & REL & $0,03 \mathrm{mg} / \mathrm{m}^{3}$ \\
\hline OSHA / EEUU & PEL & $0,03 \mathrm{mg} / \mathrm{m}^{3}$ \\
\hline INSHT / España & VLA-ED & $0,03 \mathrm{mg} / \mathrm{m}^{3}$ \\
\hline
\end{tabular}

Sin embargo, los valores límite disponibles en la bibliografía son los de Exposición Diaria, esto es, se refieren a una exposición de un trabajador durante toda su vida laboral, 8 horas diarias y 40 horas semanales durante 40 años. Al no existir Valor para Exposición de Corta Duración, se ha tomado el criterio expuesto por el INSHT de que la concentración del contaminante no debe nunca superar el nivel de 5 veces dicho valor límite16.

\section{Etapa d) agitación}

En la etapa de agitación (con el vaso tapado) la concentración de Acrilamida detectada ha sido infe- 
rior al límite de detección del método, que en este caso ha sido de $1 \mu \mathrm{g}$ para la muestra.
En la Tabla 4 se exponen los valores obtenidos y los correspondientes valores límite.

Tabla 4. Comparación entre los valores de concentración obtenidos y los valores límite del INSHT.

\begin{tabular}{|c|c|c|}
\hline Concepto & c) Pesada & d) Agitación \\
\hline Valor Límite Ambiental. VLA -ED & $0,03 \mathrm{mg} / \mathrm{m}^{3}$ & $0,03 \mathrm{mg} / \mathrm{m}^{3}$ \\
\hline Concentración $\left(\mathrm{mg} / \mathrm{m}^{3}\right)$ & $0,217 \mathrm{mg} / \mathrm{m}^{3}$ & $<0,008 \mathrm{mg} / \mathrm{m}^{3}$ \\
\hline VLA-ED x 5 & $0,15 \mathrm{mg} / \mathrm{m}^{3}$ & $0,15 \mathrm{mg} / \mathrm{m}^{3}$ \\
\hline \% sobre Valor Límite VLA -ED & $723 \%$ & $<27 \%$ \\
\hline \% sobre Valor Límite VLA -ED x 5 & $145 \%$ & $<5 \%$ \\
\hline
\end{tabular}

\section{CONCLUSIONES}

\section{Etapa c) pesada}

En la etapa c), de pesada, la concentración determinada en las condiciones de ensayo superan ampliamente el criterio citado, por lo que la situación es de riesgo higiénico.

Hay que tener en cuenta que si bien la exposición es de unos 10 minutos al mes, es decir, se trata de una exposición muy breve, el criterio seleccionado indica que su valor no debe sobrepasarse nunca. Por otra parte, al tratarse de un producto cancerígeno, la concentración debe reducirse no ya por debajo del Valor Límite, sino al más bajo nivel posible por debajo de éste.

A tal fin se recomiendan las siguientes medidas:

A. Eliminar la etapa de pesada, adquiriendo la solución ya preparada. Si esto no fuera posible:

B. Adquirir la Acrilamida prepesada, de forma que en el procedimiento la manipulación se reduzca al mínimo.

C. Realizar la adición al vaso de precipitados y la eventual pesada en vitrina de gases, tanto si se parte de cantidad prepesada, como si no.
D. Utilizar espátula normal, no vibradora.

E. Disminuir al máximo el número de pesadas, en función del consumo, del plazo de caducidad de la mezcla preparada y de la temperatura de almacenamiento.

Una vez implantadas la primera o las siguientes de estas medidas será necesario realizar una nueva avaluación higiénica, esta vez detallada, a fin de determinar si existe riesgo higiénico en las operaciones estudiadas, en la nuevas condiciones de trabajo.

\section{Etapa d) agitación}

Con el resultado obtenido cabría pensar que el riesgo higiénico en esta etapa es muy bajo. Pero habida cuenta de la peligrosidad de la sustancia se recomienda:

F. Llevar a cabo la agitación y disolución en vitrina de gases.

Cuando se realice la evaluación de la etapa de pesada, se deberá confirmar que el riesgo en esta etapa es irrelevante llevando a cabo la evaluación detallada de este riesgo higiénico en la proximidad de la vitrina de gases. 


\section{BIBLIOGRAFÍA}

1. MERCK KgaA. Ficha de Datos de Seguridad. Acrilamida. Art. Nr. 110784. Ed. 28.02.2003

2. Amersham Bioscienc. Ficha de Datos de Seguridad. Acrilamida. Cat. No. 17-1302-02. 03.09.2002

3. Allen, R. C. y Maurer, H. C. (eds.) Electrophoresis and isoelectric focusing in PAA gel. New York. 1974 (First small Conference of The Blue Fingers)

4. Polyacrylamide Gel Electrophoresis: laboratory techniques. Pharmacia Fine Chemicals.

5. Westermeier, Reiner. Electrophoresis in Practice. VCH (Wiley and Comp.)

6. NIOSH Pocket Guide to Chemical Hazards. Acrylamide. Disponible en: http://www.cdc.gov/niosh/ npg/npgd0012.html

7. Occupational Safety and Health Administration (OSHA). Hazards Infomation Bulletin. Acrylamide. Disponible en: http://www.osha.gov/dts/hib/hib_data/ hib19900727.html

8. NIOSH. The Registry of Toxic Effects of Chemical Substances. Acrylamide. Disponible en: http://www.cdc.gov/niosh/rtecs/as32bc48.html

9. International Programme on Chemical Safety, IPCS. Chemical Safety Information from Intergo- vernmental Organizations, INCHEM. Disponible en: http://www.inchem.org/documents/iarc/vol60/ m60-11.html

10. Acrylamide, 5. Summary of data reported and evaluation. Disponible en http://monographs.iarc.fr/ENG/ Monographs/vol60/volume60.pdf

11. OSHA. Método PV2004. Julio 1991. Disponible en: http://www.osha.gov/dts/sltc/methods/partial/pv2004/ 2004.html

12. OSHA. Método 21. Octubre 1980. Disponible en: http://www.osha.gov/dts/sltc/methods/organic/org021/org 021.html

13. Health and Safety Executive (HSE). Methods for the Determination of Hazardous Substances. Acrylamide in air. MDHS 57. Marzo 1987

14. UNE-EN 482:1994 Atmósferas en el lugar de trabajo. Requisitos generales relativos al funcionamiento de los procedimientos para la medición de agentes químicos.

15. Grupo INTERLAB, S.A. Informes de ensayo 597/2005 y 2365/2005. Madrid. 2005.

16. Límites de Exposición Profesional para Agentes Químicos en España. INSHT. Madrid. 2007. Disponible en: http://www.mtas.es/insht/practice/vlas.htm\#352 